\title{
Methyl siloxanes in environmental matrices and human plasma/fat from both general industries and residential areas in China
}

\author{
Lin Xu, Yali Shi, Nannan Liu, Yaqi Cai* \\ State Key Laboratory of Environmental Chemistry and Ecotoxicology, Research Center for Eco-Environmental Sciences, Chinese Academy of Sciences, Beijing 100085, China
}

\section{H I G H L I G H T S}

- Siloxanes are detected in additives/products from general industries in China.

- Their plasma concentrations in industrial workers were higher than reference group.

- Siloxanes are more likely to distribute in human fat than plasma.

- Linear but not cyclic compounds had an apparent accumulation in human fat.

- Population's half-lives of L8-L10 in human fat were about 1.49-1.80 years.

\section{A R T I C L E I N F O}

\section{Article history:}

Received 18 August 2014

Received in revised form 12 October 2014

Accepted 12 October 2014

Available online 30 October 2014

Editor: Adrian Covaci

\section{Keywords:}

Methyl siloxanes

General industries

Plasma

Abdominal fat

Accumulation

\begin{abstract}
A B S T R A C T
We investigated human exposure to methyl siloxanes in three general industries (building, automobile, and textile industries) and residential areas in China. Usage volumes of methyl siloxanes per capita in these industries were 2-5 orders of magnitudes higher than those in residential areas. Methyl siloxane concentrations in indoor air and dust samples from industrial facilities were 1-3 orders of magnitudes higher than those in residential houses. Both cyclic (D4-D6) and linear (L5-L16) siloxanes were detected in plasma of industrial workers $(1.00-252 \mathrm{ng} / \mathrm{mL}$, detection frequencies $=3.7-71 \%, \mathrm{n}=528)$, while only cyclic compounds (D4-D6) were detected in plasma of general population $(\mathrm{n}=519)$ with much lower concentrations $(1.10-7.50 \mathrm{ng} / \mathrm{mL})$ and detection frequencies (1.7-3.7\%). During the occupational exposure, anti-dust mask can reduce $30 \%$ of intake of cyclic siloxanes and 74\% of intake of linear siloxanes, respectively. In addition, PM-10 could elevate intake of linear siloxanes. Calculated fat-plasma partition ratios of methyl siloxanes (D4-D6, L6-L11) in the present study were $5.3-241 \mathrm{~mL} / \mathrm{g}$. Linear rather than cyclic siloxanes had an apparent accumulation in abdominal fat. Population's half-lives of L8-L10 in abdominal fat of general population were approximately $1.49-1.80$ years.
\end{abstract}

(c) 2014 Elsevier B.V. All rights reserved.

\section{Introduction}

Because of their low surface tension, high thermal stability and smooth texture, methyl siloxanes have been widely used for several decades in personal care products (PCPs) and industrial additives/ products, such as lubricants, polishes, paints, lacquers, and textile products (Horii and Kannan, 2008; Wang et al., 2009; SEHSC, 2011). The total annual production volumes of cyclic methyl siloxanes in USA and China, including octamethylcyclotetrasiloxane (D4), decamethylcyclopentasiloxane (D5), and dodecamethylcyclohexasiloxane

Abbreviations: E, intake rate; PCPs, personal care products; PEL, pseudo-exposure level; $\sum$ CMS, total concentrations of cyclic methyl siloxanes; $\sum$ LMS, total concentrations of linear methyl siloxanes; TVOC, total volatile organic compounds; $\mathrm{V}_{\mathrm{c}}$, usage volume of methyl siloxane per capita; $\mathrm{V}_{\mathrm{d}}$, volume of distribution.

* Corresponding author. Tel./fax: +8610 62849182.

E-mail address: caiyaqi@rcees.ac.cn (Y. Cai).
(D6), were approximately 470 and 800 million kg, respectively (CNKI, 2009; EPA, 2002). Recently, methyl siloxanes have been detected in aquatic, terrestrial, and atmospheric compartments (Dewil et al., 2007; Lu et al., 2010; Mclachlan et al., 2010; Zhang et al., 2011; Bletsou et al., 2013; Pieri et al., 2013; Lee et al., 2014).

In view of their toxic effects on human reproductive, immune, and nervous systems (Liebierman et al., 1999; He et al., 2003; OEHHA, 2007), human exposure to siloxanes has become a public health concern (Horii and Kannan, 2008; Lu et al., 2010). One previous study demonstrated that plasma concentrations of methyl siloxanes in workers from one siloxane production facility in China were much higher than those in general population (Xu et al., 2012). However, besides the workers involved in siloxane production, people in some general industries, such as building, textile, and automobile industries, also have potential exposure to methyl siloxanes due to the large usage of siloxane products (Kaj et al., 2005; Lassen et al., 2005; SEHSC, 2011), which should attract our attention because these three industries have a 
large amount of employed population - approximately 100 million in China (Zhang, 2002). However, to the best of our knowledge, there is no study on occupational exposure to methyl siloxanes in these three industries based on biological matrices of workers.

Non-occupational exposure to many typical organic pollutants, such as polyfluorinated compounds and polybrominated diphenyl ethers, can be investigated efficiently based on plasma/blood samples (Liu et al., 2009; Qin et al., 2011). However, despite the wide use in general public, methyl siloxanes were scarcely detected in plasma of general population (Flassbeck et al., 2001; Xu et al., 2012). It was difficult to efficiently evaluate non-occupational exposure to siloxanes basing on plasma samples. Because siloxanes have high log Kow values, such as 6.49 for D4, 8.03 for D5, 9.06 for D6, and 6.0 for L5 (Brooke et al., 2009a,b,c; Kaj et al., 2005), they are prone to transferring from plasma to fat (Flassbeck et al., 2003; Kala et al., 1998), indicating that human fat may be a sensitive indicator for human exposure to methyl siloxanes. As far as we know, there is lack of studies on distribution, accumulation, and elimination of methyl siloxanes in human fat during nonoccupational or occupational exposure.

In the present study, we collected industrial additives/products ( $n=33)$, environmental matrices $(n=42)$, human plasma $(n=528)$, and abdominal fat $(n=41)$ samples from seven industrial facilities involved in building, automobile, and textile industries - in northern China. Meanwhile, environmental matrices ( $\mathrm{n}=140$ ), human plasma ( $\mathrm{n}=519)$, and abdominal fat $(\mathrm{n}=249)$ samples from residential areas were collected. We systematically assessed the sources and distribution of cyclic (D4-D6) and linear (L3-L16) siloxanes in these samples. Subsequently, we estimated the influence of human and environmental factors on human intake of methyl siloxanes during occupational exposure. Finally, we investigated the accumulation and elimination potential of methyl siloxanes in abdominal fat of both occupational participants and non-occupational participants.

\section{Materials and methods}

\subsection{Sampling}

\subsubsection{Plasma and abdominal fat samples}

In total, 1047 participants were enrolled in the present study: 528 participants, as the occupational group, were from seven industrial facilities - including 2 construction sites, 2 paint production plants, 1 automobile plant, 1 engine plant, and 1 textile plant. Meanwhile, 519 participants from seven cities in northern China, without industrial work experiences, served as the control group. It should be noted that although some control participants in the present study were from the same city with the participants in our previous study (Xu et al., 2012), the participants had no overlap between these two studies. During January to March 2012, each of 487 occupational participants and 270 control participants provided one plasma sample (5 mL) voluntarily. Subsequently, during June 2012 to March 2014, 7 participants from one paint production plant, 26 participants from the engine plant, 8 participants from the textile plant, and 249 control participants, as the patients receiving abdominal operations, provided paired plasma/ abdominal fat samples. The sampling was conducted in two hospitals in Shandong Province, and written consent was provided by their institutional review boards. Each participant completed a questionnaire with auxiliary information such as age, gender, body mass index (BMI), number of daily-used PCPs, occupational history, and use of exposure protection equipment (Supplementary data, Table S1).

\subsubsection{Industrial products/additives}

During January to March 2012, 33 samples were collected, including 8 home paint product samples from two construction sites, 16 home paint products from two paint production plants, 3 car shell paint and 1 car shell polish - a cream mixture that can remove grime and scrapes from car shell - from the automobile plant, 2 machine lubricant samples from the engine plant, 2 fabric softening agent samples and 1 spot remover - a mixture of solvents plus ultrafine multiholed powder that can dissolve and remove oil stains on fabric - from the textile plant.

\subsubsection{Air and dust/soil samples}

During January to March 2012, air and dust/soil samples were collected. Each of the construction sites, paint production plants, and textile plant had two workshops, while the automobile plant and engine plant had six and nine workshops, respectively. It was difficult to obtain samples from all workshops in the latter two facilities. Therefore, in each of the seven industrial facilities, we collected indoor air $(8 \mathrm{~h})$ and floor dust samples from two workshops (named as A and B). Meanwhile, one outdoor air ( $8 \mathrm{~h}$ ) and one soil sample were also collected from each industrial facility. At each sampling site, we collected duplicate air samples using solid phase extraction cartridges as previously reported with minor modifications (Kierkegaard and Mclachlan, 2010). In brief, for collecting each air sample, two $250 \mathrm{mg}$ ENV + cartridges, rinsed with $10 \mathrm{~mL}$ of $\mathrm{n}$-hexane prior to sampling, were assembled in series and mounted under a precipitation shield with the down-facing inlets. The assembled cartridges were connected to a diaphragm pump with Teflon tubing. The pump was used to pull air through the cartridges at a flow rate of $1.0 \mathrm{~L} / \mathrm{min}$. After sampling, cartridges were sealed and stored at $-18{ }^{\circ} \mathrm{C}$. The breakthrough of methyl siloxanes during air sampling was determined by mounting a backup cartridge in series with the primary cartridge. The concentrations of methyl siloxanes in backup cartridges were approximately 145-569 times lower than those in primary cartridges, indicating that breakthrough could be neglected. Dust samples were collected using vacuum cleaners and brushes, and then sealed in glass tubes and stored at $-18{ }^{\circ} \mathrm{C}$.

The environmental factors of the studied workshops were measured (Table S2), including floor area, number of workers, vent wind speed, temperature, indoor concentrations of particulate matter (PM-10), and indoor concentrations of total volatile organic compounds (TVOC). TVOC was measured by PhoCheck 5000 portable TVOC monitor with photoionization detector (Ion Science, UK). The range of TVOC measurement is $0.01-10,000 \mathrm{mg} / \mathrm{m}^{3}$.

In addition, 60 paired indoor air ( $24 \mathrm{~h}$ )/floor dust samples and 10 paired outdoor air/soil samples were collected in residential areas.

\subsection{Standards and chemicals}

Cyclic siloxanes (D4, D5, D6), linear siloxanes [L3, L4, polydimethylsiloxane mixture (PDMS)], and tetrakis (trimethylsilyoxy) silane (M4Q) were purchased from Sigma-Aldrich (St. Louis, MO, USA). The compositions of linear siloxanes (L5-L16) in the PDMS mixture were measured (Table S3) by gas chromatography coupled with atomic emission detection (GC/AED) as reported previously (Kala et al., 1997). Methanol, ethyl acetate, and n-hexane were HPLC grade and obtained from Fisher Scientific (Fair Lawn, New Jersey, USA).

\subsection{Sample pretreatment and analysis}

\subsubsection{Additives/products}

The pretreatment referred to methods for extracting siloxanes from personal care products (Horii and Kannan, 2008; Wang et al., 2009), with some modifications. $1 \mathrm{~mL}$ of the sample, spiked with $100 \mu \mathrm{L}$ of M4Q solution (10 mg/L, internal standard), was vortexed for $5 \mathrm{~min}$ at $2500 \mathrm{rpm}$ with $3 \mathrm{~mL}$-hexane, and then extracted by ultrasonic for $40 \mathrm{~min}$. Subsequently, the mixture was centrifuged at $3000 \mathrm{rpm}$ for $10 \mathrm{~min}$, and the solvent layer was transferred into a glass tube. Each sample was extracted three times. The third extraction was carried out after soaking the sample with $3 \mathrm{~mL}$ of $\mathrm{n}$-hexane for $12 \mathrm{~h}$. 


\subsubsection{Dust/soil}

The pretreatment referred to one previous study (Lu et al., 2010), with some modifications. Dust/soil samples were sieved through a $500 \mu \mathrm{m}$ mesh sieve. $0.2 \mathrm{~g}$ of the sieved sample, spiked with $100 \mu \mathrm{L}$ of M4Q solution ( $1 \mathrm{mg} / \mathrm{L}$, internal standard), was vortexed for $5 \mathrm{~min}$ at $2500 \mathrm{rpm}$ with $10 \mathrm{~mL}$ of ethyl acetate/n-hexane mixture (1:1), and then extracted by ultrasonic for $15 \mathrm{~min}$. The mixture was centrifuged at $3000 \mathrm{rpm}$ for $15 \mathrm{~min}$ to collect the supernatant. Each sample was extracted three times. The total extract was dried by a cartridge filled with $1.0 \mathrm{~g}$ of anhydrous sodium sulfate, and then the cartridge was eluted with additional $5 \mathrm{~mL}$ of ethyl acetate/n-hexane mixture (1:1).

\subsubsection{Air}

For reducing the loss of cyclic siloxanes in the sampling cartridge during storage, the pretreatment occurred within $18 \mathrm{~h}$ after the sample collection. The method referred to one previous study (Kierkegaard and Mclachlan, 2010), with some modifications. $50 \mu \mathrm{L}$ of M4Q solution ( $1 \mathrm{mg} / \mathrm{L}$, internal standard) was spiked on the upper frit of the sampling cartridge, and then eluted with $10 \mathrm{~mL}$ of hexane.

\subsubsection{Plasma}

The pretreatment referred to one previous study (Flassbeck et al., 2001), with some modifications. $1.0 \mathrm{~mL}$ of plasma sample and $50 \mu \mathrm{L}$ of M4Q solution ( $1 \mathrm{mg} / \mathrm{L}$, internal standard) were mixed, and then $0.5 \mathrm{~mL}$ of methanol was added to precipitate proteins. The mixed sample was vortexed for $10 \mathrm{~min}$ with $2.0 \mathrm{~mL}$ of hexane, extracted by ultrasonic for $15 \mathrm{~min}$, and then centrifuged to collect the supernatant. The extraction procedure was repeated three times.

\subsubsection{Abdominal fat}

The pretreatment referred to one previous study (Flassbeck et al., 2003), with some modifications. The sample (0.1-0.2 g) spiked with $100 \mu \mathrm{L}$ of M4Q solution ( $1 \mathrm{mg} / \mathrm{L}$, internal standard) was homogenized with an IKA dispersing tool S8N-5G (Staufen, Germany), vortexed for $20 \mathrm{~min}$ at $2500 \mathrm{rpm}$ with $2 \mathrm{~mL}$ of $n$-hexane, and centrifuged at $10,000 \mathrm{rpm}$ for $10 \mathrm{~min}$ to remove particulate matter. Each sample was extracted three times. Most of lipids in the final extract were eliminated by freezing lipid filtration.

For all these categories of samples, the final extract was concentrated to $1 \mathrm{~mL}$ with a gentle stream of nitrogen for GC-MS analysis. Massto-charge ratios of ions used to monitor the signals of compounds are summarized in Table S4.

\subsection{Quality assurance/quality control}

Siloxanes are present in many consumer products and laboratory products. We made efforts to avoid the contamination during sample collection and analysis: 1) the analyst did not use hand lotions or other consumer products containing siloxanes; 2 ) before use, all glass tubes were cleaned with hexane, and then combusted at $300{ }^{\circ} \mathrm{C}$; 3) prior to use, ENV + cartridges and anhydrous sodium sulfate cartridges were immersed in hexane for $4 \mathrm{~h}$, and subsequently rinsed with $10 \mathrm{~mL}$ of hexane. After rinsing, the cartridges were dried using purified nitrogen and stored in capped glass tubes; 4) vacuum tubes were not used for blood/plasma collection because siloxanes are widely applied in these tubes as lubricant. Instead, human blood samples were drawn by silicone-free disposable syringes (KD Scientific, USA), and then transferred to glass tubes.

Field blanks of dust, plasma, fat, and industrial additives/products were prepared with siloxane-free anhydrous sodium sulfate, bovine plasma, bovine fat, and n-hexane, respectively. D4, D5, and D6 were detected in field blanks of industrial products/additives (1.1-1.6 ng/g), dust $(0.2-0.5 \mathrm{ng} / \mathrm{g})$, plasma $(0.06-0.3 \mathrm{ng} / \mathrm{mL})$, and abdominal fat (0.05-0.1 ng/g), respectively. At each sampling site, field blanks of air samples were prepared in the same manner with actual air samples, except that air was not pumped through the cartridge. The average mass of field blanks was $0.11,0.12$, and 0.14 ng per cartridge for D4, D5, and D6, respectively, while linear siloxanes were not detected. The concentrations of siloxanes in field blanks of air samples, calculated via dividing the mass of field blank by the sampling air volume, were $0.07 \mathrm{ng} / \mathrm{m}^{3}$ for $\mathrm{D} 4,0.08 \mathrm{ng} / \mathrm{m}^{3}$ for $\mathrm{D} 5$, and $0.1 \mathrm{ng} / \mathrm{m}^{3}$ for D6 after $24 \mathrm{~h}$ sampling $\left(1.44 \mathrm{~m}^{3}\right)$, while $0.21 \mathrm{ng} / \mathrm{m}^{3}$ for $\mathrm{D} 4,0.24 \mathrm{ng} / \mathrm{m}^{3}$ for $\mathrm{D} 5$, and $0.3 \mathrm{ng} / \mathrm{m}^{3}$ for D6 after $8 \mathrm{~h}$ sampling $\left(0.48 \mathrm{~m}^{3}\right)$. In the present study, the reported concentrations of siloxanes in all samples were corrected with field blanks.

LOQs of D4-D6 were determined as 10 times the standard deviation of field blank signals $(n=7)$. Because L3-L16 were not detected in field blanks, their LOQs were determined as 10 times the standard deviation of signals of field blank samples $(\mathrm{n}=7)$ spiked with target compounds at known concentrations. LOQs of siloxanes (D4-D6 and L3-L16) were 4.0-8.3 ng/g for products/additives, $0.5-1.0 \mathrm{ng} / \mathrm{g}$ for dust/soil, $0.4-$ $1.0 \mathrm{ng} / \mathrm{mL}$ for plasma, and $1.2-2.5 \mathrm{ng} / \mathrm{g}$ for abdominal fat, respectively (Table S5-S8). LOQs of siloxanes in air were $0.4-1.0 \mathrm{ng} / \mathrm{m}^{3}$ for $8 \mathrm{~h} \mathrm{sam-}$ ples $\left(0.48 \mathrm{~m}^{3}\right)$ and $0.14-0.36 \mathrm{ng} / \mathrm{m}^{3}$ for $24 \mathrm{~h}$ samples $\left(1.44 \mathrm{~m}^{3}\right)$, respectively (Table S9).

Average recoveries of siloxanes for industrial products/additives, dust/soil, plasma, and abdominal fat were $(71 \pm 2)-(84 \pm 4) \%$, $(81 \pm 3)-(94 \pm 5) \%,(89 \pm 6)-(95 \pm 6) \%$, and $(71 \pm 6)-(84 \pm 5) \%$, respectively (Table S5-S8). Sampling efficiencies of siloxanes for air were investigated using the method reported by Kierkegaard and Mclachlan (2010), with some modifications. In brief, target compounds, mixed with decachlorobiphenyl, were injected to a plug of fine glass wool inserted in ENV + cartridge barrel. The glass wool was heated to $250{ }^{\circ} \mathrm{C}$ for vaporizing both cyclic and linear siloxanes, and the vapor of siloxanes was pulled through the ENV + cartridge by diaphragm pump at flow rate of $1.0 \mathrm{~L} / \mathrm{min}$. Average sampling efficiencies of siloxanes (Table S9) were $(87 \pm 3)-(98 \pm 2) \%$ after 8 h sampling $\left(0.48 \mathrm{~m}^{3}\right)$, and $(90 \pm 3)-(98 \pm 2) \%$ after $24 \mathrm{~h}$ sampling $\left(1.44 \mathrm{~m}^{3}\right)$. The repeatability of air sampling was assessed using duplicate samples collected at the same site. Overall, relative standard deviations (RSD, $\%$ ) of siloxanes concentrations in duplicate air samples were less than $15 \%$. The reported siloxane concentration in air at each site was the average value in duplicate samples.

\subsection{Data analysis}

Treating age as both continuous and categorical variable (Seals et al., 2011), we evaluated correlations between human age and the logarithm of methyl siloxane concentration in female abdominal fat $(\mathrm{n}=$ 179) of general generation, using the following equation:

$\ln ($ methyl siloxane $)=\alpha+\beta \times$ age $+\delta \times \chi$

Where $\delta$ and $\chi$ are parameters and covariate vectors. Because the female participants in the tested group were from the same race, and had no smoking history, the covariates in this analysis merely included BMI and number of daily-used PCPs.

Subsequently, using the locally weighted regression smoother (LOESS) with bi-weight kernel, we graphed a curve of $\ln$ (methyl siloxane concentration) with the adjustment for covariates by human age. The span values of LOEES - percent of all data points to fit regression - were selected by minimizing Akaike's information criterion (Akaike, 1973). In this analysis, fat concentrations below LOQ were replaced with $\mathrm{f} \times \mathrm{LOQ}$, with $\mathrm{f}$ being the fraction of samples above LOQ.

\section{Results and discussion}

\subsection{Sources of methyl siloxanes in general industries}

In 24 home paint products collected from two construction sites and two paint production plants, total concentrations of cyclic methyl siloxanes ( $\sum$ CMS), including D4-D6, ranged from 1.2 to $336 \mu \mathrm{g} / \mathrm{g}$ [detection 
frequencies ( $\mathrm{df}$ ) = 75-79\%], while total concentrations of linear methyl siloxanes ( $\sum$ LMS), including L5-L16, ranged from 186 to 10,620 $\mu \mathrm{g} / \mathrm{g}$ ( $\mathrm{df}=63-71 \%)$. In three car shell paint samples and one car shell polish sample from the automobile plant, $\sum$ CMS (D4-D6) ranged from 712 to $1596 \mu \mathrm{g} / \mathrm{g}$ ( $\mathrm{df}=100 \%$ ), while $\sum$ LMS (L5-L16) ranged from 6700 to $16,086 \mu \mathrm{g} / \mathrm{g}(\mathrm{df}=100 \%)$. In two machine lubricant samples from the engine plant, $\sum$ CMS (D4-D6) were 1013 and $1323 \mu \mathrm{g} / \mathrm{g}$ ( $\mathrm{df}=100 \%$ ), respectively, while $\sum$ LMS (L5-L16) were 17,061 and 18,390 $\mu \mathrm{g} / \mathrm{g}$ ( $\mathrm{df}=100 \%$, respectively. In one spot remover sample and two fabric softening agent samples from the textile plant, $\sum$ CMS (D4-D6) ranged from 1995 to $8280 \mu \mathrm{g} / \mathrm{g}$ ( $\mathrm{df}=100 \%$ ), while $\sum$ CMS (L5-L16) ranged from 59,345 to $72,646 \mu \mathrm{g} / \mathrm{g}(\mathrm{df}=100 \%$ ). The detailed results were described in the Supplementary data, Table S10. Generally, linear siloxanes accounted for major proportions of total siloxanes in the studied additives/products: $64-93 \%$ in home paint products, $94-95 \%$ in car shell paint products, $81 \%$ in car shell polish sample, $93-95 \%$ in machine lubricant products, $90 \%$ in spot remover, and $96-97 \%$ in fabric softening agents.

The usage volume of methyl siloxane per capita $\left(\mathrm{V}_{\mathrm{c}}\right)$ in the studied industrial facilities was calculated via the following equation:

$V_{c}=\sum \mathrm{C}_{\mathrm{additive} / \text { product }} \times \mathrm{Q}_{\mathrm{additive} / \text { product }} / \mathrm{P}$

where $\mathrm{C}_{\text {additive/product }}$ represents methyl siloxane concentration in industrial additive/product, $Q_{\text {additive/product }}$ represents usage/production volume of additive/product per day (Table S11), and P represents population number of the studied facility. The average $V_{c}$ in the studied industrial facilities ranged from 0.1 to $260 \mathrm{~g} /$ day (Fig. S1), which were approximately 2-5 orders of magnitudes higher than those in general public ( $4.5 \mathrm{mg} / \mathrm{d}$, via application of PCPs) in China (Lu et al., 2011). It should be noted that besides the studied samples, other additives/ products potentially containing methyl siloxanes were not investigated, which could result in the estimated $V_{c}$ values in these industrial facilities lower than the true values.

\subsection{Concentrations of methyl siloxanes in environmental matrices}

\subsubsection{Residential houses}

In indoor air samples from residential houses $(n=60)$, no linear compound was detected, while two cyclic compounds - D4 ( df = $67 \%$ ) and D5 ( $\mathrm{df}=83 \%$ ) - were detected, with $\sum$ CMS ranging from 45.4 to $139 \mathrm{ng} / \mathrm{m}^{3}$. In indoor dust samples $(\mathrm{n}=60), \sum$ CMS (D4-D6) and $\sum$ LMS (L8-L12) were 23.3-73.5 ng/g $(\mathrm{df}=25-83 \%)$ and 18.0$156 \mathrm{ng} / \mathrm{g}$ ( $\mathrm{df}=40-92 \%)$, respectively. Statistically speaking, the number of daily-used PCPs had correlations with both $\sum \mathrm{CMS}\left(\mathrm{R}^{2}=0.29\right.$, $p<0.05)$ and $\sum$ LMS $\left(R^{2}=0.23, p<0.05\right)$ in indoor dust samples, indicating that PCPs could be one important source of methyl siloxanes in indoor environment of residential houses (Lu et al., 2010; Lu et al., 2011).

\subsubsection{Industrial facilities}

In summary, methyl siloxane concentrations in indoor air and dust samples from these industrial facilities were 1-3 orders of magnitudes higher than those from residential houses (Fig. 1a). Cyclic compounds (D4-D6) were detected in indoor air samples $(n=14)$ from these industrial facilities, with $\sum$ CMS ranging from 58.6 to $572 \mu \mathrm{g} / \mathrm{m}^{3}$ ( $\mathrm{df}=100 \%$ ). Although linear siloxanes had higher concentrations than cyclic compounds in most industrial additives/products, their total concentrations $\left(0.05-11.2 \mu \mathrm{g} / \mathrm{m}^{3}, \mathrm{df}=0-53 \%\right)$ in indoor air samples were much lower than those of cyclic siloxanes, which should be due to their lower vapor pressures (Kaj et al., 2005; Kochetkov et al., 2001). $\sum$ CMS (D4-D6) in indoor dust samples $(\mathrm{n}=14)$ from industrial facilities were $2.74-50.4 \mu \mathrm{g} / \mathrm{g}$ ( $\mathrm{df}=73-100 \%$, Fig. 1b). Different with results obtained from air samples, linear compounds (L5-L16) in dust samples had higher concentrations ( $\sum$ LMS $=184-6700 \mu \mathrm{g} / \mathrm{g}$, $\mathrm{df}=100 \%$ ) than cyclic compounds.
In the studied workshops $(\mathrm{n}=14)$, positive correlations $\left(\mathrm{R}^{2}=0.44\right.$, $p<0.05$ ) were observed between $\sum$ CMS in indoor air and $\sum$ CMS in dust samples, both of which were affected by their usage volume $(p<0.05)$. $\sum$ LMS in dust samples had positive correlations $\left(\mathrm{R}^{2}=0.80\right.$, $p<0.05$ ) with their usage volume. However, different with cyclic siloxanes, $\sum$ LMS in dust samples were not significantly $(p>0.05)$ correlated with $\sum$ LMS in air samples. We also explored the influence of some environmental parameters (such as temperature, vent wind speed, TOC, and PM-10) on linear siloxanes' dust-air partition. Multiple linear regression indicated that PM-10 concentrations had significantly positive correlation ( $p<0.05$, Table S12) with natural logarithm of dust-air partition coefficients of linear siloxanes, perhaps because linear siloxanes have low volatility and high lipophilicity, and tend to be absorbed by suspended particles (such as PM10) in air.

\subsection{Concentrations of methyl siloxanes in human plasma}

\subsubsection{General population}

In 519 plasma samples from general population, no linear siloxane was detected, while three cyclic siloxanes (D4-D6) were detected, with concentrations ranging from $1.10-5.95 \mathrm{ng} / \mathrm{mL}$ ( $\mathrm{df}=3.7 \%$ ), 1.98 $6.22 \mathrm{ng} / \mathrm{mL}(\mathrm{df}=3.7 \%)$, and $1.85-7.50 \mathrm{ng} / \mathrm{mL}(\mathrm{df}=1.7 \%)$ for $\mathrm{D} 4, \mathrm{D} 5$, and D6, respectively (Table 1). This result was consistent with previous studies from China and Germany (Xu et al., 2012; Flassbeck et al., 2001), which reported that methyl siloxanes were hardly found in plasma of general population. Although Hanssen et al. (2013) reported higher detection frequencies of cyclic siloxanes $-85 \%, 18 \%$, and $5 \%$ for D4, D5, and D6, respectively - in plasma of general population (postmenopausal women) from Norway, their concentrations were also at low levels 2.93-12.7 ng/mL, 1.44-3.94 ng/mL, and 2.67-3.17 ng/mL for D4, D5, and D6, respectively. Generally, methyl siloxanes had scarce distribution in plasma of general population, perhaps due to their limited nonoccupational exposure and fast plasma elimination (Plotzke et al., 2000; Reddy et al., 2003; Tobin et al., 2008).

\subsubsection{Workers in industries}

In the seven industrial facilities, median concentrations of D4, D5, and D6 in plasma samples were $2.50-25.5 \mathrm{ng} / \mathrm{mL}(\mathrm{df}=3.7-$ $67 \%$ ), 3.44-38.0 ng/mL ( $\mathrm{df}=3.7-71 \%$ ), and $4.40-10.1 \mathrm{ng} / \mathrm{mL}$ ( $\mathrm{df}=1.7-38 \%$ ), respectively, which were $1.2-10$ times higher than those in general population (Table 1). In the seven industrial facilities, median concentrations of L5, L6, L7, L8, L9, L10, L11, L12, L13, L14, L15, and L16 in plasma samples were <LOQ$21.0 \mathrm{ng} / \mathrm{mL}$ ( $\mathrm{df}=0-28 \%$ ), $5.50-102 \mathrm{ng} / \mathrm{mL}(\mathrm{df}=3.7-40 \%), 1.70-$ $16.0 \mathrm{ng} / \mathrm{mL}(\mathrm{df}=8.9-40 \%), 2.93-16.6 \mathrm{ng} / \mathrm{mL} \quad(\mathrm{df}=8.9-$ $40 \%),<\mathrm{LOQ}-12.3 \mathrm{ng} / \mathrm{mL}(\mathrm{df}=0-29 \%),<\mathrm{LOQ}-14.4 \mathrm{ng} / \mathrm{mL}(\mathrm{df}=$ $0-30 \%$ ), $<\mathrm{LOQ}-17.4 \mathrm{ng} / \mathrm{mL}(\mathrm{df}=0-27 \%),<\mathrm{LOQ}-16.4 \mathrm{ng} / \mathrm{mL}(\mathrm{df}=0-$ $26 \%$ ), $<$ LOQ $-18.2 \mathrm{ng} / \mathrm{mL}(\mathrm{df}=0-28 \%),<\mathrm{LOQ}-51.3 \mathrm{ng} / \mathrm{mL}(\mathrm{df}=0-$ $32 \%$ ), $<$ LOQ $-23.5 \mathrm{ng} / \mathrm{mL}$ ( $\mathrm{df}=0-10 \%)$, and $<\mathrm{LOQ}-30.6 \mathrm{ng} / \mathrm{mL}(\mathrm{df}=$ $0-10 \%$ ), respectively. Methyl siloxanes in plasma of female workers had no significant difference $(p>0.05)$ with those in male workers from the same workshop. In addition, because methyl siloxanes in plasma can reach steady state quickly (Xu et al., 2012), there was no significant relationship $(p>0.05)$ between $\sum$ CMS (or $\sum$ LMS) in plasma samples of workers and their ages (or years worked in industrial facilities).

\subsection{Factors affecting intake of methyl siloxanes}

We calculated the daily intake of methyl siloxanes, named as "pseudo-exposure level" (PEL), according to the hypothesis that no hygiene practice was carried out in industrial or residential areas. The calculation methods and results were described in detail in the Supplementary data. The median total PELs of cyclic siloxanes (D4-D6) via inhalation + ingestion in residential houses was $173 \mathrm{ng} / \mathrm{d}$, which was 21 times higher than that of linear siloxanes (L8-L12, $8.1 \mathrm{ng} / \mathrm{d}$ at 


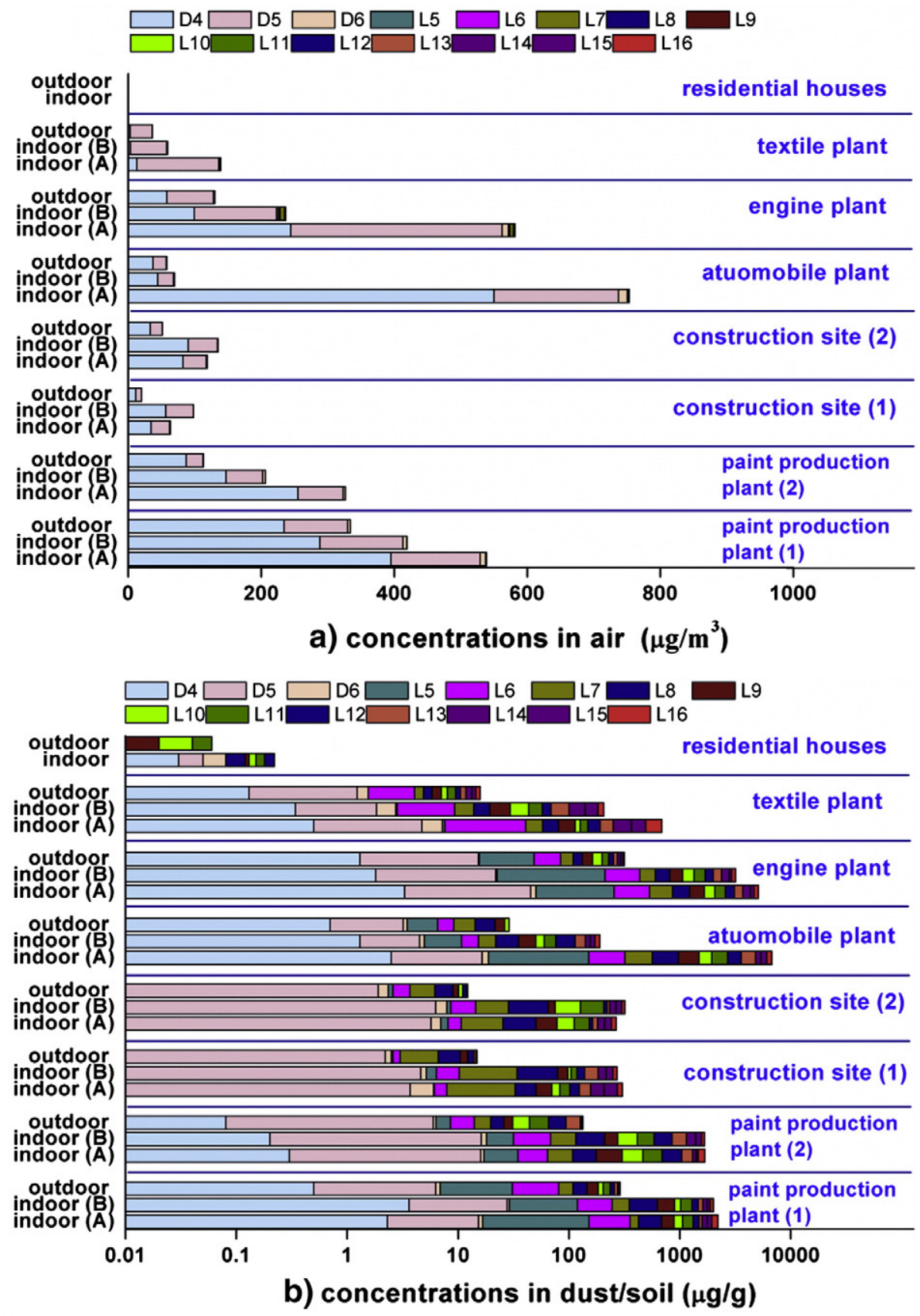

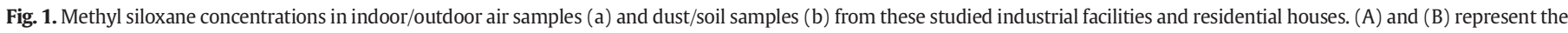
names of workshops.

median). The median total PELs of all siloxanes (D4-D6 and L8-L12) via inhalation + ingestion in residential houses were $180 \mathrm{ng} / \mathrm{d}$, which was approximately 100 times lower than their reported dermal exposure level $(18.5 \mu \mathrm{g} / \mathrm{d}$ at median) in the general population in China ( $\mathrm{Lu}$ et al., 2011).

Due to the application of protective clothing and gloves, intakes of siloxanes via dermal adsorption in industrial facilities were not estimated. The total PELs of D4-D6 (via inhalation + ingestion) in the seven industrial facilities were $56.3-720 \mu \mathrm{g} / \mathrm{d}$, which were 1.4-26 times higher than those of L3-L16 (4.3-179 $\mu \mathrm{g} / \mathrm{d})$. Overall, inhalation was the dominant exposure pathway (99.8-99.9\%, Table S13) for volatile cyclic siloxanes, while dust ingestion was the main exposure pathway (33-98\%, 78\% at average, Table S13) for linear siloxanes. The total PELs of all siloxanes in these industrial facilities were 64.3-860 $\mu \mathrm{g} / \mathrm{d}$ (Table S13), which were $\sim 2$ orders of magnitudes higher than those in residential houses
$(18.68 \mu \mathrm{g} / \mathrm{d}$ at median, via inhalation + ingestion + dermal adsorption). This result indicated that higher concentrations and detection frequencies of methyl siloxanes in plasma of industrial workers than those in general population should be attributed to their higher exposure levels in industrial facilities.

In the studied 14 workshops, $\sum$ CMS or $\sum$ LMS in plasma of workers $(\mathrm{n}=299)$ had no significant relationship $(p>0.05)$ with their PELs, perhaps because different environmental and human factors in these workshops affected human intake behavior, which was discussed in detail as follows.

In general, the plasma concentrations of chemicals depend on their intake as the following equation:

$C_{p} / E=t_{1 / 2} /\left(0.693 \times V_{d} \times W\right)$ 
Table 1

Methyl siloxane concentrations $(\mathrm{ng} / \mathrm{mL})$ in human plasma samples.

\begin{tabular}{|c|c|c|c|c|c|c|c|c|c|c|c|c|c|c|c|c|c|c|}
\hline & & D4 & D5 & D6 & L3 & L4 & L5 & L6 & L7 & L8 & L9 & L10 & L11 & L12 & L13 & L14 & L15 & L16 \\
\hline \multirow[t]{4}{*}{ Paint production plant $1(\mathrm{n}=49)$} & df $(\%)$ & 29 & 26 & 19 & & & & 39 & 40 & 12 & 29 & 28 & 11 & & & & & \\
\hline & $\min$ & 3.32 & 14.5 & 4.83 & & & & 3.00 & 1.13 & 2.05 & 1.93 & 2.21 & 3.14 & & & & & \\
\hline & $\max$ & 75.1 & 60.3 & 23.5 & & & & 23.6 & 23.0 & 12.4 & 11.4 & 28.0 & 12.8 & & & & & \\
\hline & median $^{\mathrm{a}}$ & 25.5 & 38.0 & 8.85 & & & & 9.22 & 4.23 & 8.10 & 2.95 & 7.31 & 6.90 & & & & & \\
\hline \multirow[t]{4}{*}{ Paint production plant $2(\mathrm{n}=20)$} & df $(\%)$ & 15 & 40 & 30 & & & & 40 & 25 & 15 & 5.0 & 20 & & & & & & \\
\hline & $\min$ & 3.10 & 2.26 & 3.38 & & & & 2.93 & 1.78 & 2.01 & & 3.6 & & & & & & \\
\hline & $\max$ & 7.01 & 49.0 & 13.2 & & & & 24.0 & 5.50 & 3.64 & & 8.44 & & & & & & \\
\hline & median & 3.53 & 23.2 & 8.50 & & & & 10.1 & 2.24 & 2.93 & 4.22 & 5.50 & & & & & & \\
\hline \multirow[t]{4}{*}{ Automobile plant $(\mathrm{n}=179)$} & df $(\%)$ & 15 & 23 & 25 & & & 8.9 & 10 & 8.9 & 8.9 & 8.9 & 8.9 & 8.9 & 8.9 & 8.9 & 20 & 10 & 10 \\
\hline & $\min$ & 2.07 & 2.18 & 4.16 & & & 12.9 & 3.44 & 11.6 & 5.24 & 6.88 & 10.1 & 13.3 & 2.25 & 1.65 & 1.00 & 1.55 & 1.68 \\
\hline & $\max$ & 17.9 & 32.2 & 40.1 & & & 22.3 & 123 & 22.3 & 9.45 & 12.1 & 18.3 & 21.4 & 4.22 & 4.65 & 14.0 & 50.4 & 72.4 \\
\hline & median & 8.59 & 16.0 & 8.48 & & & 16.4 & 102 & 16.0 & 7.56 & 9.21 & 14.4 & 17.4 & 2.85 & 3.03 & 5.00 & 23.5 & 30.6 \\
\hline \multirow[t]{4}{*}{ Engine plant $(\mathrm{n}=164)$} & df (\%) & 38 & 37 & 38 & & & 28 & 27 & 29 & 27 & 26 & 30 & 27 & 26 & 28 & & & \\
\hline & $\min$ & 2.77 & 4.00 & 1.98 & & & 4.25 & 4.33 & 1.77 & 1.30 & 1.00 & 1.67 & 1.15 & 1.10 & 9.50 & & & \\
\hline & $\max$ & 23.2 & 125 & 16.2 & & & 252 & 87.0 & 44.4 & 23.3 & 14.0 & 40.0 & 23.0 & 13.0 & 32.0 & & & \\
\hline & median & 13.5 & 22.3 & 8.90 & & & 21.0 & 7.85 & 11.2 & 8.02 & 5.40 & 13.2 & 5.00 & 3.23 & 9.10 & & & \\
\hline \multirow[t]{4}{*}{ Textile plant $(\mathrm{n}=61)$} & df $(\%)$ & 67 & 71 & 11 & & & & 29 & 15 & 40 & & & & & & & & \\
\hline & $\min$ & 1.40 & 1.83 & 2.79 & & & & 10.8 & 1.03 & 1.10 & & & & & & & & \\
\hline & $\max$ & 6.47 & 19.8 & 6.07 & & & & 20.6 & 3.95 & 22.3 & & & & & & & & \\
\hline & median & 3.69 & 9.49 & 5.20 & & & & 17.0 & 1.70 & 16.6 & & & & & & & & \\
\hline \multirow[t]{4}{*}{ Construction site $1(\mathrm{n}=28)$} & df $(\%)$ & 39 & 32 & 11 & & & & 14 & 21 & 17 & 21 & 11 & 11 & 14 & 7.1 & 32 & & \\
\hline & $\min$ & 1.80 & 5.00 & 5.00 & & & & 5.90 & 8.00 & 1.38 & 3.60 & 1.78 & 3.17 & 9.50 & 11.5 & 4.91 & & \\
\hline & $\max$ & 12.5 & 20.0 & 11.7 & & & & 11.0 & 22.0 & 16.8 & 14.4 & 5.00 & 10.0 & 30.0 & 14.2 & 65.0 & & \\
\hline & median & 4.00 & 12.8 & 6.20 & & & & 6.95 & 13.7 & 7.25 & 6.90 & 2.44 & 7.67 & 16.4 & 12.9 & 51.3 & & \\
\hline \multirow[t]{4}{*}{ Construction site $2(\mathrm{n}=27)$} & df $(\%)$ & 33 & 22 & 11 & & & & 3.7 & 15 & 22 & 7.4 & 19 & 15 & 11 & 19 & & & \\
\hline & $\min$ & 2.34 & 8.45 & 6.50 & & & & & 7.67 & 10.4 & 9.43 & 5.72 & 2.31 & 4.12 & 12.3 & & & \\
\hline & $\max$ & 13.0 & 23.8 & 15.2 & & & & & 14.3 & 28.6 & 15.2 & 18.7 & 11.7 & 13.0 & 39.0 & & & \\
\hline & median & 5.07 & 15.0 & 10.1 & & & & 5.50 & 9.03 & 17.8 & 12.3 & 9.36 & 3.86 & 9.97 & 18.2 & & & \\
\hline \multirow[t]{4}{*}{ General population $(\mathrm{n}=519)$} & $\mathrm{df}(\%)$ & 3.7 & 3.7 & 1.7 & & & & & & & & & & & & & & \\
\hline & $\min$ & 1.10 & 1.98 & 1.85 & & & & & & & & & & & & & & \\
\hline & $\max$ & 5.95 & 6.22 & 7.50 & & & & & & & & & & & & & & \\
\hline & median & 2.50 & 3.44 & 4.40 & & & & & & & & & & & & & & \\
\hline
\end{tabular}

Abbreviations: df, detection frequency; min, minimum concentration; max, maximum concentration.

a Median value of concentrations exceeding the LOQ.

where $C_{p}$ represents plasma concentration of chemical; E represents intake rate; $t_{1 / 2}$ represents half life in plasma; $V_{d}$ represents the volume of distribution; W represents body weight (Vestergren and Cousins, 2009).

In the present study, the intake rate was calculated based on EPA protocols. This calculation method has assumed a "same exposure scenario" in all workshops, which should have same environmental and human factors. In fact, these factors may be not really same in these workshops. Therefore, intake rates in the Eq. (3) should be modified as:

$\mathrm{C}_{\mathrm{p}} /\left(\mathrm{E}_{\mathrm{o}} \times \alpha\right)=\mathrm{t}_{1 / 2} /\left(0.693 \times \mathrm{V}_{\mathrm{d}} \times \mathrm{W}\right)$

where $E_{o}$ was the intake rate in the assumed "same exposure scenario", which was named as "pseudo-exposure level" (PEL) in the present study; $\alpha$ was the modified coefficient of the factors in the industrial facilities. Because the $t_{1 / 2}$ of methyl siloxanes, $V_{d}$, and body weight (RSD\% $=2.8 \%$ in the present study) can be assumed constant, Eq. (4) showed that $\alpha$ has positive correlation with ratios of $C_{p} / E_{o}$. Therefore, in the present study, substituting $\mathrm{C}_{\mathrm{p}} / \mathrm{E}_{\mathrm{o}}$ for $\alpha$, we studied influence of some environmental and human factors on $C_{p} / E$ of methyl siloxanes in the studied workshops. In this analysis, plasma concentrations below LOQ were replaced with $\mathrm{f} \times \mathrm{LOQ}$, with $\mathrm{f}$ being the fraction of samples above LOQ.

\subsubsection{Hygiene practices}

Anti-dust masks $(0.3 \mu \mathrm{m})$ were used in some workshops of these facilities (Table S2). We found that for 139 workers without anti-dust mask, the median ratios of $C_{p} / E_{o}$ were $0.043 \mathrm{~d} / \mathrm{L}$ for cyclic siloxanes and $1.08 \mathrm{~d} / \mathrm{L}$ for linear siloxanes, respectively. While for 160 workers with anti-dust mask, the median ratios of $C_{p} / E_{o}$ for cyclic $(0.032 \mathrm{~d} / \mathrm{L})$ and linear $(0.28 \mathrm{~d} / \mathrm{L})$ siloxanes were approximately $30 \%$ and $74 \%$ lower than those for workers without anti-dust mask, respectively (Fig. S2). This phenomenon could be explained by the following reasons: cyclic methyl siloxanes (D4-D6) with high vapor pressure (0.03-1.05 Torr) mainly exist in air, while linear compounds with low vapor pressure tend to exist in dust (Kaj et al., 2005; Kochetkov et al., 2001). In general, anti-dust mask could effectively reduce the exposure to pollutants via dust ingestion, but could not effectively reduce their exposure via inhalation.

\subsubsection{Other affecting factors}

Using multiple linear regression, we assessed the influences of population density, temperature, vent wind speed, TVOC, and PM-10 on $\mathrm{Cp} / \mathrm{E}_{\mathrm{o}}$ ratios in workshops $(\mathrm{n}=7)$ without anti-dust mask. Table 2 showed that no factor had apparent correlation $(p>0.05)$ with $\mathrm{Cp} / \mathrm{E}_{\mathrm{o}}$ ratios of cyclic compounds. For linear compounds, there were positive correlations between $\mathrm{Cp} / \mathrm{E}_{\mathrm{o}}$ ratios and PM-10 concentrations (Table 2). Due to their high organic carbon-water partition coefficients (PCKOCWIN, 2008), linear compounds may be adsorbed by atmospheric particulate matter with an aerodynamic diameter of $10 \mu \mathrm{m}$ or smaller (such as PM-10), and then could enter the human respiratory system. In general, PM-10 concentrations in non-industrial areas were less than $0.1 \mathrm{mg} / \mathrm{m}^{3}$ (Oomen and Lijzen, 2004). According to $20 \mathrm{~L} / \mathrm{min}$ of inhalation rate (Wilford et al., 2004), PM-10 mass inhaled by an adult is $2.88 \mathrm{mg} /$ day when its concentration was $0.1 \mathrm{mg} / \mathrm{m}^{3}$. This value is only $5.8 \%$ of dust ingestion rate $(50 \mathrm{mg} /$ day for adults) in EPA protocols (EPA, 2011), and is always negligible when considering the total exposure to a pollutant. However, in industrial workshops in the present study, the median PM-10 concentration was $0.55 \mathrm{mg} / \mathrm{m}^{3}$, and the PM10 mass inhaled by an adult was $15.8 \mathrm{mg} /$ day, which was about $31.6 \%$ of dust ingestion rate. Furthermore, due to large specific surface area and surface energy of PM-10, the concentrations of methyl siloxanes in PM-10 may be higher than those in dust (with higher aerodynamic diameter than PM-10) on the floor. Overall, these results indicated that PM-10 would elevate intake of linear siloxanes via inhalation, especially in industrial area. 
Table 2

Results of multiple regression analysis on $C_{p} / E_{o}$ values in the studied workshops.

\begin{tabular}{|c|c|c|c|c|c|c|c|c|}
\hline & \multicolumn{4}{|c|}{ Cyclic compounds } & \multicolumn{4}{|c|}{ Linear compounds } \\
\hline & $\beta$ & $95 \% \mathrm{CI}$ & SE & $p$ & $\beta$ & $95 \% \mathrm{CI}$ & SE & $p$ \\
\hline Vent speed & -0.195 & $-0.411-0.020$ & -0.188 & 0.076 & -0.178 & $-6.507-6.151$ & -0.006 & 0.956 \\
\hline TVOC & -0.004 & $-0.009-0.001$ & -0.158 & 0.117 & -0.204 & $-0.356-0.051$ & -0.248 & 0.094 \\
\hline PM-10 & -0.056 & $-0.134-0.022$ & -0.117 & 0.160 & 8.339 & 6.038-10.064 & 0.563 & 0.000 \\
\hline Temperature & 0.025 & $0.006-0.043$ & 0.345 & 0.090 & 0.922 & $0.382-1.462$ & 0.416 & 0.100 \\
\hline Population density & -0.369 & $-1.484-0.746$ & -0.056 & 0.514 & -50.35 & $-80.07-17.63$ & -0.224 & 0.130 \\
\hline
\end{tabular}

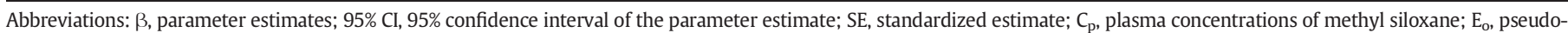
exposure level.

3.5. Methyl siloxane distribution, accumulation and elimination in abdominal fat

\subsubsection{Distribution}

Concentrations of D4, D5, and D6 in abdominal fat of general population $(\mathrm{n}=249)$ were $4.00-141 \mathrm{ng} / \mathrm{g}(\mathrm{df}=38 \%), 3.10-77.5 \mathrm{ng} / \mathrm{g}$ ( $\mathrm{df}=18 \%$ ), and $4.08-77.2 \mathrm{ng} / \mathrm{g}(\mathrm{df}=35 \%)$, respectively. Despite no detection in plasma of general population, three linear compounds (L8, L9, and L10) were detected in fat of general population, with concentrations in the range of $1.20-44.8 \mathrm{ng} / \mathrm{g}(\mathrm{df}=27 \%), 1.52-$ $50.1 \mathrm{ng} / \mathrm{g}(\mathrm{df}=30 \%)$, and $2.30-78.4 \mathrm{ng} / \mathrm{g}(\mathrm{df}=29 \%)$ for L8, L9, and L10, respectively. The total concentrations of all siloxanes (D4-D6, L8-L10) in female abdominal fat ( $83.5 \mathrm{ng} / \mathrm{g}$ at median, $\mathrm{n}=179$ ) were significantly $(p<0.05)$ higher than those in male ones ( $45.0 \mathrm{ng} / \mathrm{g}$ at median, $\mathrm{n}=70$ ), which may be explained by the following reasons: (1) in China, female consume most proportion (approximately 92\%) of PCPs - the major sources of non-occupational exposure to methyl siloxanes (Mintel, 2012); (2) physiologically female have a larger volume of adipose tissues and a slower metabolism for methyl siloxanes than male (Luu and Hutter, 2001).

In 41 abdominal fat samples of participants from industrial facilities, D4-D6 and L6-L11 were detected. Concentrations of D4, D5, D6, L6, L7, L8, L9, L10, and L11 were 86.8-306 ng/g ( $\mathrm{df}=100 \%), 35.8-170 \mathrm{ng} / \mathrm{g}$ $(\mathrm{df}=100 \%), 58.5-124 \mathrm{ng} / \mathrm{g}(\mathrm{df}=100 \%), 42.7-250 \mathrm{ng} / \mathrm{g}(\mathrm{df}=100 \%)$, $50.5-198 \mathrm{ng} / \mathrm{g}(\mathrm{df}=100 \%), 38.9-311 \mathrm{ng} / \mathrm{g}(\mathrm{df}=100 \%), 66.8-$ $186 \mathrm{ng} / \mathrm{g}(\mathrm{df}=80 \%), 44.4-296 \mathrm{ng} / \mathrm{g}(\mathrm{df}=80 \%)$, and $30.5-$ $175 \mathrm{ng} / \mathrm{g}(\mathrm{df}=80 \%)$, respectively (Table S14).

In the present study, the partition ratios of siloxanes (D4-D6, L6L11) between paired fat and plasma samples ranged from 5.3 to $241 \mathrm{~mL} / \mathrm{g}$ (Table S15). Due to their high log Kow values (Brooke et al., 2009a,b,c; Kaj et al., 2005), methyl siloxanes are prone to transferring from plasma to fat/tissue. Previous studies have showed that during inhalation exposure, ${ }^{14} \mathrm{C}$-D4 and ${ }^{14} \mathrm{C}$-D5 concentrations in fat of rats are 1-2 orders of magnitudes than those in plasma (Plotzke et al., 2000; Tobin et al., 2008).

\subsubsection{Accumulation and elimination}

We plotted methyl siloxane concentrations in female abdominal fat ( $n=179$ ) of general population vs human ages (Fig. 2 ), and found that both $\sum$ CMS (D4-D6) and $\sum$ LMS (L8-L10) in participants at the age of 66-76 were apparently lower than those at the age of 16-66. One of the reasons for lower siloxane concentrations in fat of participants at the age of 66-76 may be their lower exposure levels of siloxanes via PCPs application: 1) in this study, participants at the age of 66-76 had much lower number of daily-used PCPs ( 0.7 at average) than those (5.2 at average) at the age of $16-66 ; 2$ ) the major categories of PCPs used by the group at the age of 66-76 were toothpastes and toilet soaps. The daily usage of siloxanes per capita via application of toothpastes and toilet soaps in China was about $0.5 \mathrm{mg} / \mathrm{d}$, which was merely $12 \%$ of their total daily usage via application of PCPs (Lu et al., 2011); 3 ) due to different application methods, exposure time to chemicals via application of toothpastes and toilet soaps $(0.08-0.33 \mathrm{~h} / \mathrm{d})$ was lower than that those via application of other PCPs, such as face cream, liquid foundation, and body lotion (3-24 h/d).

We performed multiple linear regression analysis to evaluate the relationship between $\ln$ (methyl siloxane concentrations) in fat and three individual characteristics, including age, BMI, and number of daily-used PCPs. Table 3 showed that both $\ln \left(\sum\right.$ LMS $)$ and $\ln \left(\sum \mathrm{CMS}\right)$ had significant $(p<0.05)$ correlations with number of daily-used PCPs, indicating the importance of PCPs application in the non-occupational exposure to methyl siloxanes. It should be noted that besides PCPs, there should be other exposure sources of siloxanes in residential houses. For examples, as we discussed in Section 1, home paints can contain siloxanes; in addition, siloxanes are widely used in home electrical/electronic devices as insulating agent (Lu et al., 2010). Siloxanes in these products could also volatilize into air and distribute in dust.

With adjustment for covariates (BMI and number of daily-used PCPs), cyclic compounds (D4-D6) in fat had no significant $(p>0.05)$ increasing tendency with age (LOEES regression, Fig. 3a), suggesting that repeated daily non-occupational exposure would not result in the accumulation of these compounds in female human fat. D4-D6 in fat could be exchanged into blood, and then quickly eliminated via exhalation (Plotzke et al., 2000). In addition, these compounds could transfer to liver, and then be rapidly metabolized (via oxidation and ring clearage) to dimethylsilanediol and methylsilanetriol, etc. generally, the half-lives of D4-D6 in blood were very short - approximately tens of hours (Reddy et al., 2003).

Different with cyclic compounds, the significantly positive correlation $(p<0.05)$ between linear compounds (L8-L10) and human ages from 16-66 were observed (Fig. 3b), indicating that L8-L10 perhaps accumulate in human fat during non-occupational exposure. Several previous studies predicted that linear methyl siloxanes with molecular weight higher than 1000 could not bio-accumulate because the molecules are too large to pass through biological membranes (Annelin and Frye, 1989). However, homologues with molecular weight lower than 1000, such as L8-L10, perhaps pass through biological membranes, and then distribute in tissue/fat. Due to their lower volatility, elimination rates of linear siloxanes via exhalation in fat would be lower than those of cyclic compounds. In addition, it was reported that hexamethyldisiloxane (L2) could be metabolized via oxidation in liver (Varaprath et al., 2003). L8-L10, as the homologues of L2, could undergo the similar metabolism. The accumulation of L8-L10 in fat indicated their metabolism rates in liver may be slower than volatile cyclic compounds (D4-D6), perhaps because their molecular weights were larger. At present, because there was no literature on the metabolism of L8-L10 in human body, our speculation could not be proved.

Fig. 3b showed that with age ranging from 66 to 76, L8-L10 concentrations in fat had decreasing trends, which should be because the intake of these compounds in this age group was too low to saturate their fast elimination in fat. Using the first-order elimination model, we assessed that half-lives of L8, L9, and L10 in abdominal fat of this age group were approximately $1.63,1.49$, and 1.80 years, respectively. It should be notable that these results for L8-L10 did not represent their physiological half-lives, and they should be named as "population's half-lives". Because these participants at the age of 

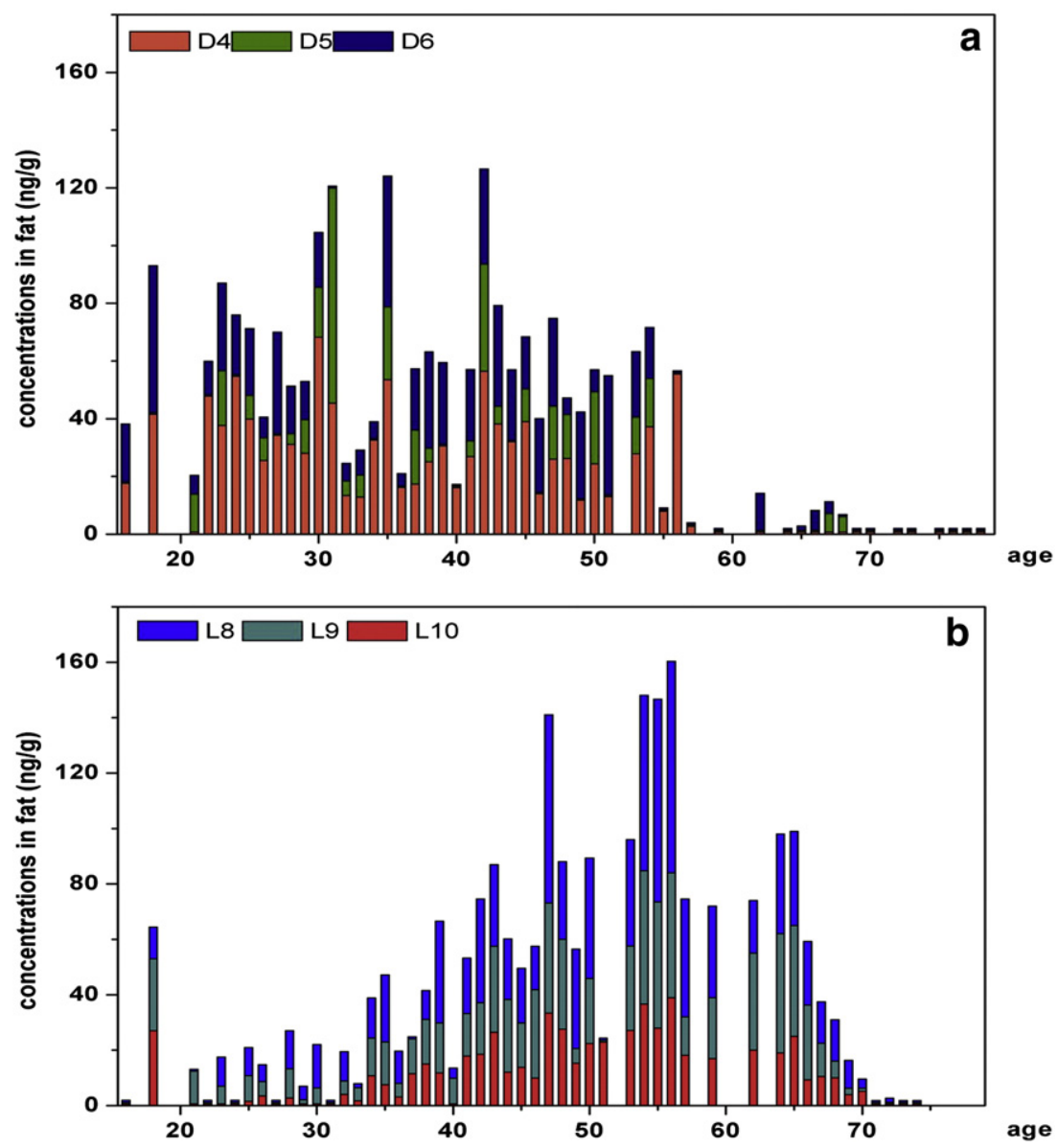

Fig. 2. Average concentrations of cyclic (a) and linear (b) methyl siloxanes in female fat $(\mathrm{n}=179)$ from general population and their ages.

66-76 still used limited PCPs, the physiological half-lives of L8-L10 would be smaller than our estimated results.

In the present study, based on the cross-sectional samples, the assessment for methyl siloxanes accumulation in fat of general population had following limitations: (1) we substituted the number of daily-used PCPs for the daily usage volume of methyl siloxanes. Although the substituting characteristic perhaps had positive correlation with daily usage volume of methyl siloxanes, it could result in the deviation of the assessment; (2) the participants perhaps misreported their individual characteristics, such as the number of daily-used PCPs.

Due to the limited samples, the linear regression model but not LOESS was used to assess correlation between total concentrations of cyclic (or linear) methyl siloxanes in fat and occupationally exposed years of workers. For cyclic compounds (D4-D6), no significant result $(p>0.05)$ was found in any industrial facility. For linear compounds (L6-L11), a significant result $\left(\mathrm{R}^{2}=0.44, p<0.05\right)$ was found in the engine plant, but not in paint production plant 1 or the textile plant.

\section{Conclusions}

Due to vast usage in industrial additives/products, methyl siloxane concentrations in both environmental matrices and human biological matrices from building, automobile, and textile industries were higher than those from general public, suggesting the serious occupational exposure in these industries in China. At present, basic hygiene practices in industrial facilities can effectively reduce the exposure to linear rather than cyclic siloxanes. Methyl siloxanes in human fat have much higher concentrations than those in plasma. During both occupational and non-occupational exposure, cyclic methyl siloxanes could not accumulate in human fat, while linear compounds have apparent accumulation potential.

Table 3

Results of multiple regression analysis on $\ln \left(\sum \mathrm{CMS}\right)$ and $\ln \left(\sum \mathrm{LMS}\right)$ in female abdominal fat.

\begin{tabular}{|c|c|c|c|c|c|c|c|c|}
\hline & \multicolumn{4}{|c|}{$\ln \left(\sum \mathrm{CMS}\right)$} & \multicolumn{4}{|c|}{$\ln \left(\sum \mathrm{LMS}\right)$} \\
\hline & $\beta$ & $95 \% \mathrm{CI}$ & SE & $p$ & $\beta$ & $95 \% \mathrm{CI}$ & SE & $p$ \\
\hline Number of daily-used PCPs & 0.732 & 0.499-0.964 & 0.118 & 0.000 & 0.608 & $0.351-0.866$ & 0.130 & 0.000 \\
\hline Age & -0.025 & $-0.042-0.009$ & 0.008 & 0.080 & 0.065 & $0.045-0.085$ & 0.010 & 0.000 \\
\hline BMI & 0.051 & $-0.110-0.212$ & 0.082 & 0.535 & -0.088 & $-0.275-0.100$ & 0.095 & 0.357 \\
\hline
\end{tabular}

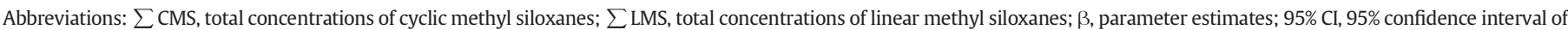
the parameter estimate; SE, standardized estimate. 

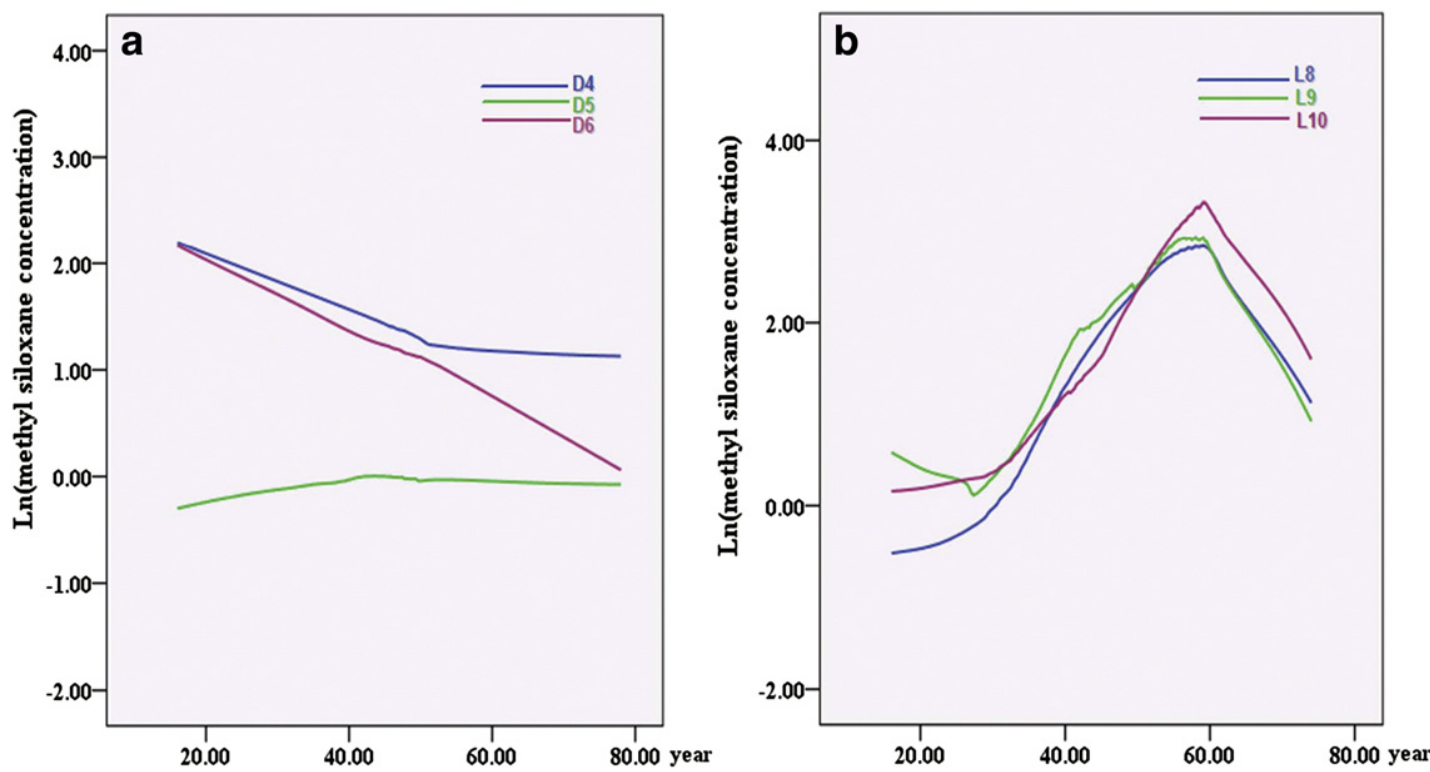

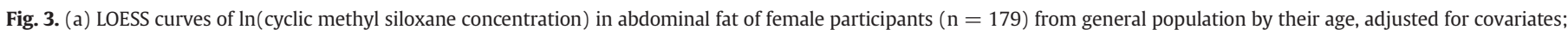
(b) LOESS curves of $\ln$ (linear methyl siloxane concentration) in abdominal fat of female participants $(\mathrm{n}=179$ ) from general population by their age, adjusted for covariates.

\section{Acknowledgment}

This work was supported by the Strategic Priority Research Program of the Chinese Academy of Sciences (XDB14010201) and the National Natural Science Foundation of China (No. 41023005, 2132100).

\section{Appendix A. Supplementary data}

Supplementary data to this article can be found online at http://dx. doi.org/10.1016/j.scitotenv.2014.10.039.

\section{References}

Akaike $\mathrm{H}$. Information theory and an extension of the maximum likelihood principle. In: Petrov BN, Csaki F, editors. Second international symposium on information theory; 1973.

Annelin RB, Frye CL. The piscine bioconcentration characteristics of cyclic and linear oligomeric permethylsiloxanes. Sci Total Environ 1989;83:1-11. (267-281).

Bletsou AA, Asimakopoulos AG, Stasinakis AS, Thomaidis NS, Kannan K. Mass loading and fate of linear and cyclic siloxanes in a wastewater treatment plant in Greece. Environ Sci Technol 2013;47(4):1824-32.

Brooke DN, Crookes MJ, Gray D, Robertson S. Environmental risk assessment report: decamethylcyclopentasiloxane. Bristol: Environment Agency of England and Wales; 2009a.

Brooke DN, Crookes MJ, Gray D, Robertson S. Environmental risk assessment report: dodecamethylcyclohexasiloxane. Bristol: Environment Agency of England and Wales; 2009b.

Brooke DN, Crookes MJ, Gray D, Robertson S. Environmental risk assessment report: octamethylcyclotetrasiloxane. Bristol: Environment Agency of England and Wales; 2009c.

CNKI. Available from: http://www.cnki.com.cn/Article/CJFDTotal-YJGF200905013.htm, 2009. (in Chinese)

Dewil R, Appels L, Baeyens J, Buczynska A, Vaeck LV. The analysis of volatile siloxanes in waste activated sludge. Talanta 2007;74(1):14-9.

EPA. Available from: http://www.epa.gov/oppt/iur/tools/data/2002-vol.htm, 2002.

EPA. Exposure factors handbook. Chapter 5 - soil and dust ingestion; 2011.

Flassbeck D, Pfleiderer B, Grümping R, Hirner AV. Determination of low molecular weight silicones in plasma and blood of women after exposure to silicone breast implants by GC/MS. Anal Chem 2001;73:606-11.

Flassbeck D, Pfleiderer B, Klemens P, Heumann KG, Eltze E, Hirner AV. Determination of siloxanes, silicon, and platinum in tissues of women with silicone gel-filled implants. Anal Bioanal Chem 2003;375:356-62.

Hanssen L, Warner NA, Braathen T, Odland J, Lund E, Nieboer E, et al. Plasma concentrations of cyclic volatile methylsiloxanes (cVMS) in pregnant and postmenopausal Norwegian women and self-reported use of personal care products (PCPs). Environ Int 2013;51:82-7.

He B, Rhodes-Brower S, Miller MR. Octamethylcyclotetrasiloxane exhibits estrogenic activity in mice via ER alpha. Toxicol Appl Pharmacol 2003;192:254-61.
Horii Y, Kannan K. Survey of organosilicone compounds, including cyclic and linear siloxanes, in personal-care and household products. Arch Environ Contam Toxicol 2008 55:701-10.

Kaj L, Schlabach M, Andersson J, Palm Cousins A, Schmidbauer N, Brorström-Lundén E. Siloxanes in the Nordic environment. Copenhagen: Nordic Council of Ministers; 2005.

Kala SV, Lykissa ED, Lebovitz RM. Detection and characterization of poly(dimethylsiloxane)s in biological tissues by GC/AED and GC/MS. Anal Chem 1997;69:1267-72.

Kala SV, Lykissa ED, Neely MW, Lieberman MW. Low molecular weight silicones are widely distributed after a single subcutaneous injection in mice. Am J Pathol 1998; 152(3):645-9.

Kierkegaard A, Mclachlan MS. Determination of decamethylcyclopentasiloxane in air using commercial solid phase extraction cartridges. J Chromatogr A 2010;1217: 3557-60.

Kochetkov A, Smith JS, Ravikrishna R, Valsaraj KT, Thibodeaux LJ. Air-water partition constants for volatile methyl siloxanes. Environ Toxicol Chem 2001;20(10):2184-8.

Lassen C, Hansen CL, Mikkelsen SH, Maag J. Siloxanes-consumption, toxicity and alternatives. Environmental project no. 1031 2005. Copenhagen: Danish Ministry of the Environment; 2005.

Lee S, Moon HB, Song GJ, Ra K, Kannan K. A nationwide survey and emission estimates of cyclic and linear siloxanes through sludge from wastewater treatment plants in Korea. Sci Total Environ 2014;497-498:106-12.

Liebierman MW, Lykissa ED, Barrios R, Qu CN, Kala G, Kala SV. Cyclosiloxanes produce fatal liver and lung damage in mice. Environ Health Perspect 1999;107:161-5.

Liu JY, Li JG, Luan Y, Zhao YF, Wu YN. Geographical distribution of perfluorinated compounds in human blood from Liaoning Province, China. Environ Sci Technol 2009;43:4044-8.

Lu Y, Yuan T, Yun SH, Wang WH, Wu Q, Kannan K. Occurrence of cyclic and linear siloxanes in indoor dust from China, and implications for human exposures. Environ Sci Technol 2010;44:6081-7.

Lu Y, Yuan T, Wang WH, Kannan K. Concentrations and assessment of exposure to siloxanes and synthetic musks in personal care products from China. Environ Pollut 2011;159:3522-8.

Luu HMD, Hutter JC. Bioavailability of octamethylcyclotetrasiloxane (D4) after exposure to silicones by inhalation and implantation. Environ Health Perspect 2001;109: 1095-101.

Mclachlan MS, Kierkegaard A, Hansen KM, Egmond RV, Christensen JH, Skjøth CA Concentrations and fate of decamethylcyclopentasiloxane (D5) in the atmosphere. Environ Sci Technol 2010;44(14):5365-70.

Mintel. Available from: http://china.mintel.com/china/China_Reports_Man_Toiletries/ index.html, 2012. (in Chinese).

OEHHA. Toxicity data review: decamethylcyclopentasiloxane (D5). Available from: http://www.arb.ca.gov/toxics/dryclean/oehhad5review.pdf, 2007.

Oomen AG, Lijzen JPA. Relevancy of human exposure via house dust to the contaminants lead and asbestos. Report no: 711701037. Bilthoven, The Netherlands: National Institute for Public Health and the Environment; 2004 (available at http://www.rivm.nl/ en/).

PCKOCWIN (Organic Carbon Partition Coefficient Program for Windows), 2008. Version 2 00. Washington (DC): United States Environmental Protection Agency, Office of Pollution Prevention and Toxics; Syracuse (NY): Syracuse Research Corporation. Exposure Assessment Tools and Models.

Pieri F, Katsoiannis A, Martellini T, Hughes D, Jones KC, Cincinelli A. Occurrence of linear and cyclic volatile methyl siloxanes in indoor air samples (UK and Italy) and their isotopic characterization. Environ Int 2013;59:363-71. 
Plotzke KP, Crofoot SD, Ferdinandi ES, Beattie JG, Reitz RH, Mcnett DA, et al. Disposition of radioactivity in fischer 344 rats after single and multiple inhalation exposure to $\left[{ }^{14} \mathrm{C}\right]$ octamethylcyclotetrasiloxane $\left(\left[{ }^{14} \mathrm{C}\right] \mathrm{D} 4\right)$. Drug Metab Dispos 2000 28:192-204.

Qin YY, Leung CKM, Lin CK, Leung AOW, Wang HS, Giesy JP, et al. Halogenated POPs and PAHs in blood plasma of Hong Kong residents. Environ Sci Technol 2011;45: $1630-7$.

Reddy MB, Dobrev ID, Plotzke KP, Andersen ME, Reitz RH, Morrow P, et al. A physiologically based pharmacokinetic model for inhalation of octamethylcyclotetrasiloxane (D4) in human during rest and exercise. Toxicol Sci 2003;72:3-18.

Seals R, Bartell SM, Steenland K. Accumulation and clearance of perfluorooctanoic acid (PFOA) in current and former residents of an exposed community. Environ Health Perspect 2011;119(1):119-24.

Silicones Environmental, Health and Safety Council of North America (SEHSC). Available from: http://www.sehsc.com/d5.asp, 2011

Tobin JM, Mcnett DA, Durham JA, Plotzke KP. Disposition of decamethylcyclopentasiloxane in Fischer 344 rats following single or repeated inhalation exposure to ${ }^{14} \mathrm{C}$ decamethylcyclopentasiloxane $\left({ }^{14} \mathrm{C}-\mathrm{D} 5\right)$. Inhal Toxicol 2008;20(5):513-31.
Varaprath S, Mcmahon JM, Plotzke KP. Metabolites of hexamethyldisiloxane and decamethylcyclopentasiloxane in Fischer 344 rat urine - a comparison of a linear and a cyclic siloxane. Drug Metab Dispos 2003;31(2):206-14.

Vestergren R, Cousins IT. Tracking the pathways of human exposure to perfluorocarboxylates. Environ Sci Technol 2009;43:5565-75.

Wang R, Moody RP, Koniecki D, Zhu JP. Low molecular weight cyclic volatile methylsiloxanes in cosmetic products sold in Canada: implication for dermal exposure. Environ Int 2009;35:900-4.

Wilford BHT, Zhu J, Shoeib M, Jones KC. Passive sampling survey of polybrominated diphenyl ether flame retardants in indoor and outdoor air in Ottawa, Canada: implications for sources and exposure. Environ Sci Technol 2004;38:5312-8.

Xu L, Shi YL, Wang T, Dong ZR, Su WP, Cai YQ. Methyl siloxanes in environmental matrices around a siloxanes production facility, and their distribution and elimination in plasma of exposed population. Environ Sci Technol 2012;46(21):11718-26.

Zhang C. Available from: http://epub.cnki.net/kns/brief/default result.aspx, 2002.

Zhang ZF, Qi H, Ren NQ Li YF, Gao DW, Kannan K. Survey of cyclic and linear siloxanes in sediment from the Songhua River and in sewage sludge from wastewater treatment plants, northeastern China. Arch Environ Contam Toxicol 2011;60:204-11. 